\title{
Three-dimensional volumetric analysis of the maxillary sinus: a cone-beam computed tomography study
}

\author{
M. Gulec ${ }^{1}$, M. Tassoker ${ }^{1}$, G. Magat ${ }^{1}$, B. Lale², S. Ozcan ${ }^{1}$, K. Orhan ${ }^{3,4}$ \\ ${ }^{1}$ Department of Oral and Maxillofacial Radiology, Necmettin Erbakan University, Faculty of Dentistry, Konya, Turkey \\ 2Department of Orthodontics, Necmettin Erbakan University, Faculty of Dentistry, Konya, Turkey \\ ${ }^{3}$ Department of Dentomaxillofacial Radiology, Faculty of Dentistry, Ankara University, Ankara, Turkey \\ ${ }^{4}$ OMFS IMPATH Research Group, Department of Imaging and Pathology, Faculty of Medicine, \\ University of Leuven and Oral and Maxillofacial Surgery, University Hospitals Leuven, Belgium
}

[Received: 19 July 2019; Accepted: 15 September 2019]

\begin{abstract}
Background: This study aimed to determine the volumetric size of the maxillary sinus and investigate the effect of gender and age on maxillary sinus volume (MSV) using cone-beam computed tomography (CBCT) images in a Turkish subpopulation.

Materials and methods: This retrospective volumetric CBCT study was carried out on 133 individuals (84 females, 49 males) between 8 and 51 years old. MSV was measured using the MIMICS 21.0 software (Materialise HQ Technologielaan, Leuven, Belgium). All statistical analyses were performed using the SPSS 21.0 (SPSS, Chicago, IL, USA) software. Mean and standard deviation of both maxillary sinuses measurements were calculated and compared to gender and age. $P$ values $<0.05$ were considered to indicate statistical significance.

Results: Mean volume of the right maxillary sinus was $13.173 \mathrm{~cm}^{3}$, while for the left was $13.194 \mathrm{~cm}^{3}$. There was no significant difference between right and left maxillary sinus volumes $(p>0.05)$. There was no significant correlation between MSV and age $(p>0.05)$. It was found that MSV did not change according to gender $(p>0.05)$.

Conclusions: Right and left maxillary sinus volumes were not different from each other. Gender and age were not found to be related to maxillary sinus volume. (Folia Morphol 2020; 79, 3: 557-562)
\end{abstract}

Key words: maxillary sinus, cone-beam computed tomography, volumetric analysis

\section{INTRODUCTION}

The maxillary sinuses are a pair of pyramid-shaped cavities which are covered with epithelium, filled with air and can be in various shapes and sizes. They are located in the maxillary bones just below the orbit. The floor of the sinus is composed of the alveolar process and its apex extends laterally towards and occasionally into the zygomatic bone [20]. The anatomy and the possible variations of the paranasal sinuses should be comprehensively known to successfully treat sinonasal disorders and to prevent complications in head and neck surgery [9]. 
The maxillary sinus, which is classified within the paranasal sinuses, is used for post mortem identification in forensic medicine because it can remain intact even in incinerated victims [20]. Besides, the maxillary sinus, having the highest volume of the paranasal sinuses, is significant in the field of dentistry because of its anatomical position with clinical dentistry [25]. It begins to develop in the $10^{\text {th }}$ week of intrauterine development and reaches a volume of $6-8 \mathrm{~cm}^{3}$ which is filled with fluid upon birth [19]. The maxillary sinus has two postnatal periods at which it grows rapidly; the first period is between the ages of $0-3$ and the second between 7 and 12 . It continues to develop slowly from age 12 until it becomes fully mature [4, 22]. The maxillary sinus reaches its adult size after permanent dentition around ages 18-20; the average maxillary sinus volume (MSV) in adults is observed to be $15 \mathrm{~cm}^{3}[3,6,19]$.

The pneumatisation of the maxillary sinus is the extension of the sinus towards the alveolar process. During development, pneumatisation is a physiological occurrence in which the sinus increases in volume and fills with air. The disappearance of teeth roots and resorption of the alveolar crest after dental extraction, especially from the maxillary posterior area, is a significant factor that affects pneumatisation [7, 31]. The shape and size of the maxillary sinus are known to be affected by factors such as genetics, the environment, and infections [16]. The maxillary sinus can be affected by a maxillary teeth-induced infection while pathology in the maxillary sinus may also affect the teeth. Simple tooth extraction or implant treatment may result in a complication that can affect all craniofacial structures. As a result, a good understanding and anatomical evaluation of the region is crucial [24]. Moreover, morphometric knowledge about the maxillary sinus is essential for an otolaryngologist and neurosurgeon to choose the most suitable surgical procedure and prevent damage to the craniomaxillofacial structures; this morphometric study was conducted for this purpose. In the literature; panoramic radiograph, lateral cephalometry, computed tomography $(\mathrm{CT})$, cone-beam computed tomography $(C B C T)$, magnetic resonance imaging were used to measure MSV. The literature shows that a limited number of studies were done on assessing MSV with CBCT [2]. In this study, we use CBCT to bilaterally determine MSV and how it could vary with age and gender.

\section{MATERIALS AND METHODS}

\section{Patient selection}

This study included the use of CBCT images of patients referred for various reasons to the Necmettin Erbakan University, Faculty of Dentistry, Department of Oral and Maxillofacial Radiology between 2013 and 2019. This study was approved by the Ethics Committee of Faculty of Dentistry. Three thousand CBCT images in the radiology archive were examined retrospectively.

The CBCT images were examined for various reasons without considering age; of the images examined, the ones that displayed sufficient diagnostic qualities were included in our study.

The exclusion criteria of our study are; exhibition of any missing tooth in the upper or lower jaw (except the third molar teeth), pathology in the maxillofacial region, bone disease, artefact images with poor diagnostic quality, maxillary sinus or graft surgery, maxillary sinus pathology, skeletal asymmetries, craniofacial traumas and developmental anomalies such as palatal cleft.

The original sample size of 133 subjects was determined by powerful software with the assumption of a maxillary sinus volume of $16.74 \pm 5.28 \mathrm{~cm}^{3}$ based on a previous study [30], and the power being $90 \%$ and the 2-sided alpha 0.05 . The estimated sample size was 65 subjects; however, considering the possible loss to follow-up, 133 subjects were decided to be recruited for sample size.

This retrospective volumetric CBCT study was carried out on 133 individuals (84 females, 49 males) between ages 8 and 51 . All right and left MSVs of the individuals were calculated separately (a total of 266 MSVs were recorded by the same observer).

\section{Imaging and screening procedures}

All CBCT scans were obtained by using a 3D Accuitomo 170 (J. Morita Corp., Kyoto, Japan) within the parameters of $90 \mathrm{kVp}, 5 \mathrm{~mA}$ and $17.5 \mathrm{~s}$ exposure time and $17 \times 12 \mathrm{~cm}$ image area. All CBCT images were recorded in the Digital Imaging and Communications in Medicine (DICOM) format. A 2.66 GHz Intel Xeon PC with $3.25 \mathrm{~Gb}$ of RAM, Windows XP Professional operating system, and 27-inch flat-panel colour display with a resolution of $2560 \times 1600$ pixels (U2711 HTM; Dell, Round Rock, TX, USA) was used to examine the scans. Dixel ${ }^{\mathrm{TM}} 2.03 \mathrm{D}$ imaging software (J. Morita Europe $\mathrm{GmbH}$, Dietzenbach, Germany) was used to evaluate the images. CBCT images in DICOM format were transferred to a personal computer where right 


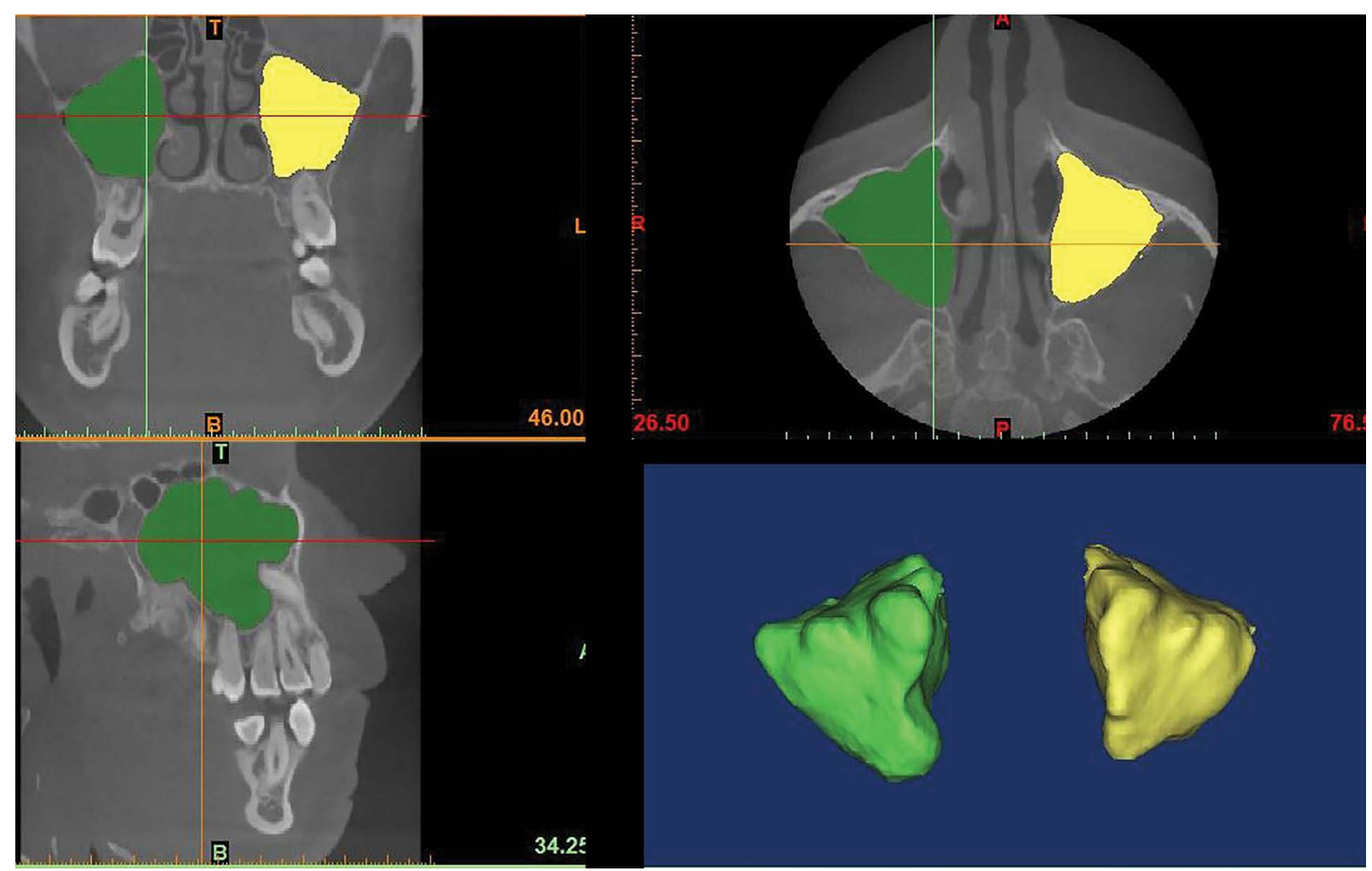

Figure 1. Three-dimensional reconstruction and measurement of the maxillary sinuses.

and left MSVs were measured using the MIMICS 21.0 software (Materialise HQ Technologielaan, Leuven, Belgium). Hounsfield Unit (HU) threshold values for maxillary sinuses were determined on transferred and displayed images. The borders of the maxillary sinuses were determined afterward. The maxillary sinuses were cropped along the following borders: around the bone structure and the narrowest space of the ostium between the processus uncinatus and infundibulum. After this, three-dimensional (3D) models of the sinuses were created and the volumes of the right and left sinuses were calculated separately by giving different colours to the sinuses of the same patient (Fig. 1) [21].

\section{Statistical analysis}

All statistical analyses were performed using the SPSS 21.0 (SPSS, Chicago, IL, USA) software. The measurements were repeated by the same observer at a 1-month interval. The Wilcoxon matched-pairs signed-rank test was used for the repeated measurements to investigate the reliability of the observer. Mean and standard deviations of both maxillary sinus measurements were calculated and compared with gender and age. The conformity of the parameters to normal distribution was analysed using the Kol-
mogorov-Smirnov test. Since the distribution of the variables did not conform to the normal distribution, non-parametric tests were applied. Wilcoxon signed sequence, Kruskal-Wallis and Mann-Whitney $U$ tests were used alongside the Spearman correlation analysis to compare the measurements. $P$ values $<0.05$ were considered to indicate statistical significance.

\section{RESULTS}

Our study was conducted on 133 individuals (84 females, 49 males). The mean age of all individuals was $18 \pm 6.1$ years (for women $19 \pm 6.3$, for men $17 \pm 5.6$ years; no notable age difference was found between the two genders). Since there was no significant difference observed between the first and subsequent measurements, the first measurements were used in the data analysis ( $p>0.05)$.

The mean MSV of all the individuals was found to be $13.173 \pm 4.187 \mathrm{~cm}^{3}$ for the right sinus and $13.194 \pm 4.626 \mathrm{~cm}^{3}$ for the left. There was no significant difference between right and left MSVs ( $p>0.05)$ (Table 1).

When the relationship between MSV and gender was investigated, there was no statistically significant difference observed $(p>0.05)$. The mean right MSV in women and men were $12.559 \pm 3.773 \mathrm{~cm}^{3}$ and 
Table 1. The mean value of right and left maxillary sinus volumes according to gender

\begin{tabular}{lcccc}
\hline Gender & Right volume $\left[\mathbf{c m}^{3}\right]$ & SD & Left volume $\left[\mathbf{c m}^{3}\right]$ & SD \\
\hline Female & 12.559 & 3.773 & 12.493 & 3.768 \\
Male & 14.227 & 4.669 & 14.396 & 5.654 \\
Total & 13.173 & 4.187 & 13.194 & 4.626 \\
$P$ & 0.060 & & 0.094 & \\
\hline
\end{tabular}

SD — standard deviation

$14.227 \pm 4.669 \mathrm{~cm}^{3}$, respectively. The mean left MSV was $12.493 \pm 3.768 \mathrm{~cm}^{3}$ in women, while being $14.396 \pm 5.654 \mathrm{~cm}^{3}$ in men (Table 1). The mean MSVs of 133 individuals were evaluated to investigate the relationship between age and mean MSVs, no correlation was found ( $p>0.05)$.

\section{DISCUSSION}

In addition to displaying anatomical proximity to dental structures and having the largest volume among the paranasal sinuses, the maxillary sinus is of great importance because of its contribution to the development of facial morphology and its susceptibility to infections [13]. Also, it is important in forensic medicine. In this study, bilateral MSVs of male and female individuals of varying ages were calculated and differences between the individuals were examined bilaterally.

To date, different methods have been used for evaluating pneumatisation in paranasal sinuses and different results may be based on this [2]. It is emphasized that the segmentation method, which is more diagnostic than the linear measurement based on geometric method, is the most accurate and reliable in terms of measuring sinus volume. The maxillary sinus has no uniform boundary and these linear measurements may be different from the reality [2]. Additionally, injectable materials can be used for measuring sinus volume, but this cannot be performed in in vivo conditions and the procedure is difficult [2]. Anatomical measurements that are made on cadavers will result in misleading and inaccurate outcomes due to the considerable soft tissue loss [2]. In this study, 3D segmentation was performed with MIMICS software on the CBCT images of 133 individuals to measure the volume of maxillary sinuses bilaterally. It was reported that MIMICS measurements highly correlated with the actual organ volumes [28].

The reports related the relationship between age and MSV are controversial. While some researchers kept the age range to a wide extent such as 16-79 [23] or 0-80 [14], some limited it to under [11] or over [8] 18 years of age. CBCT archives of individuals conforming to the inclusion criteria mentioned for this study were examined and age parameters were kept at a range of 8-51 years. In our study, the mean age of 133 subjects, 84 of whom were female and 49 were male, were examined as $18 \pm 6.1$ years. Different results may be related to the different age distributions of the samples.

As a result of research conducted on people of varying races and geographies, it was observed that these different factors can alternate MSV values. The right and left MSV values of the same individual can also be significantly different from each other. In a study conducted on the CT images of individuals of Japanese background, the mean of the MSV was found to be higher than in other races (the mean of the right MSV: $23.6 \mathrm{~cm}^{3}$, the mean of the left MSV: $20.9 \mathrm{~cm}^{3}$ ). This result was associated with the difference in the height-weight ratio of this ethnicity and the differences in the method used in volume measurement [17]. In a study conducted on European and Zulu cadavers that were separated according to their race and gender, it was observed that the mean MSVs of the two races were significantly different from each other statistically (for the European race: the mean of the right MSV: $16.39 \mathrm{~cm}^{3}$, the mean of the left MSV: $16.42 \mathrm{~cm}^{3}$; for the Zulu race: the mean of the right MSV: $11.13 \mathrm{~cm}^{3}$, the mean of the left MSV: $10.99 \mathrm{~cm}^{3}$ ) [12].

In the literature, although most studies found no statistically significant differences between the left and right MSV values of the same individual [5, 27], this was not the case for studies conducted on the images of individuals who had nasal septal deviation [23]. In this study, the mean of the right MSV was calculated to be $13.173 \pm 4.187 \mathrm{~cm}^{3}$ and the mean of the left MSV was $13.194 \pm 4.626 \mathrm{~cm}^{3}$. Consistent with the literature, no significant difference was found be- 
tween them. The potential different dentition status of the individuals on the right and left side should also be considered. The patients with missing teeth (except third molars) were excluded. Kalabalik and Tarim Ertas [15] examined the CBCT images of 252 patients, all of whom were missing maxillary premolar and molar teeth, between the ages of 12-85; an increase in MSV with missing teeth was observed, especially in patients over 61 .

Some studies in the literature found differences in MSV values between genders and it was stated that MSV values of male commonly higher $[8,10,14]$, hence concluded that this result can be used in gender verification in cadavers [1]; however, other studies found no differences associated with gender $[5,26,29]$. In our study, the mean of the MSV was calculated as $14.311 \pm 5.057 \mathrm{~cm}^{3}$ in males and $12.526 \pm 3.628 \mathrm{~cm}^{3}$ in females, which meant that no statistically significant difference was found between them. The variation in the results can be due to differences in female-male distribution, race, and methods used in MSV measurement.

In the literature, there are many studies investigating the relationship between age and volume. In a study performed by Emirzeoglu and Sahin [10] on 77 patients over the age of 18 , a negative correlation between age and volume was observed. Ariji and Kuroki [5] investigated the relationship between age and sinus volume based on $115 \mathrm{CT}$ images of patients; the results showed an increase in MSV until the age of 20, and a gradual decline thereafter. Karakas and Kavakli [16] researched mastoid cell pneumatisation and paranasal sinus volumes in relation to age based on the $\mathrm{CT}$ images of 91 patients between the ages of 5-55; the observations showed a significant increase in volume with age. Kalabalik and Tarim Ertas [15] examined the CBCT images of 252 patients, all of whom were missing maxillary premolar and molar teeth, between the ages of 12-85 in their study; an increase in MSV with missing teeth was observed, especially in patients over 61 . The results of the present study showed no significant correlation between MSV and age. The individuals included in this study did not exhibit a proportionate distribution for age, and missing teeth is one of the exclusion criteria; for this reason, varying results can be observed in comparison to other studies. Our study showed similar findings to Sahlstrand-Johnson et al. [27] who investigated maxillary and frontal sinus volumes in relation to age and gender using the CT images of 60 patients over the age of 18 , no correlation was observed. Besides, a study that analysed the relationship between paranasal sinus volume and age in 60 patients ranging from ages 18-63 showed no significant correlation [18]. Different results may be related to the different age distributions of the samples and dentition status of the individuals. The alteration in adult MSV with aging may be related to the loss of maxillary posterior teeth.

\section{CONCLUSIONS}

This study found no notable correlation between age/gender and right/left MSVs in a Turkish subpopulation. The MSV values acquired from this study may be used to evaluate and plan surgical procedures concerning the maxillary sinus region, as well as being a reference to radiologists, orthodontists, oral/ /maxillofacial surgeons and otolaryngologists in future research. Because MSV does not vary with age and gender, it can't be useful in forensic medicine and tooth loss may be an effective factor on MSV.

\section{REFERENCES}

1. Akhlaghi M, Bakhtavar K, Kamali A, et al. The diagnostic value of anthropometric indices of maxillary sinuses for sex determination using CT-scan images in Iranian adults: A cross-sectional study. J Forensic Leg Med. 2017; 49: 94-100, doi: 10.1016/j.jflm.2017.05.017, indexed in Pubmed: 28614757.

2. Aktuna Belgin C, Colak M, Adiguzel O, et al. Three-dimensional evaluation of maxillary sinus volume in different age and sex groups using CBCT. Eur Arch Otorhinolaryngol. 2019; 276(5): 1493-1499, doi: 10.1007/s00405-01905383-y, indexed in Pubmed: 30879193.

3. Anagnostopoulou S, Venieratos D, Spyropoulos N. Classification of human maxillar sinuses according to their geometric features. Anat Anz. 1991; 173(3): 121-130, indexed in Pubmed: 1789468.

4. Apuhan T, Yıldırım YS, Ozaslan H. Is there any developmental relationship between mastoid pneumatization and adenoid tissue volume? Int J Pediatr Otorhinolaryngol. 2011; 75(3): 415-419, doi: 10.1016/j.ijporl.2010.12.018, indexed in Pubmed: 21239065.

5. Ariji $Y$, Kuroki T, Moriguchi $S$, et al. Age changes in the volume of the human maxillary sinus: a study using computed tomography. Dentomaxillofac Radiol. 1994; 23(3): 163-168, doi: 10.1259/dmfr.23.3.7835518, indexed in Pubmed: 7835518.

6. Benninger MS, Ferguson BJ, Hadley JA, et al. Adult chronic rhinosinusitis: definitions, diagnosis, epidemiology, and pathophysiology. Otolaryngol Head Neck Surg. 2003; 129 (3 Suppl): S1-32, doi: 10.1016/s0194-5998(03)01397-4, indexed in Pubmed: 12958561.

7. Chanavaz M. Maxillary sinus: anatomy, physiology, surgery, and bone grafting related to implantology - eleven years of surgical experience (1979-1990). J Oral Implantol. 1990; 16(3): 199-209, indexed in Pubmed: 2098563. 
8. Çolakoğu G. Sagital yönde farklı maksiller konuma sahip bireylerde maksiller sinüs hacimlerinin dental volumetrik tomografi kullanılarak morfometrik olarak karşılaştırılması. [Phd Thesis]. ístanbul: Marmara University, 2013.

9. Eggesbø HB. Radiological imaging of inflammatory lesions in the nasal cavity and paranasal sinuses. Eur Radiol. 2006; 16(4): 872-888, doi: 10.1007/s00330-005-0068-2, indexed in Pubmed: 16391905.

10. Emirzeoglu $M$, Sahin B, Bilgic $S$, et al. Volumetric evaluation of the paranasal sinuses in normal subjects using computer tomography images: a stereological study. Auris Nasus Larynx. 2007; 34(2): 191-195, doi: 10.1016/j. anl.2006.09.003, indexed in Pubmed: 17084569.

11. Endo $T$, Abe $R$, Kuroki $H$, et al. Cephalometric evaluation of maxillary sinus sizes in different malocclusion classes. Odontology. 2010; 98(1): 65-72, doi: 10.1007/s10266009-0108-5, indexed in Pubmed: 20155510.

12. Fernandes CL. Volumetric analysis of maxillary sinuses of Zulu and European crania by helical, multislice computed tomography. J Laryngol Otol. 2004; 118(11): 877-881, doi: 10.1258/0022215042703705, indexed in Pubmed: 15638975 .

13. Fernández JS, Escuredo JA, Del Rey AS, et al. Morphometric study of the paranasal sinuses in normal and pathological conditions. Acta Otolaryngol. 2000; 120(2): 273-278, doi: 10.1080/000164800750001080, indexed in Pubmed: 11603789.

14. Jun BC, Song SW, Park CS, et al. The analysis of maxillary sinus aeration according to aging process; volume assessment by 3-dimensional reconstruction by high-resolutional CT scanning. Otolaryngol Head Neck Surg. 2005; 132(3): 429-434, doi: 10.1016/j.otohns.2004.11.012, indexed in Pubmed: 15746857.

15. Kalabalık F, Tarım Ertaş E. Investigation of maxillary sinus volume relationships with nasal septal deviation, concha bullosa, and impacted or missing teeth using cone-beam computed tomography. Oral Radiol. 2019; 35(3): 287-295, doi: 10.1007/s11282-018-0360-x, indexed in Pubmed: 30484216.

16. Karakas S, Kavakli A. Morphometric examination of the paranasal sinuses and mastoid air cells using computed tomography. Ann Saudi Med. 2005; 25(1): 41-45, doi: 10.5144/02564947.2005.41, indexed in Pubmed: 15822493.

17. Kawarai KF, Ogawa T, Nishizaki K, et al. Volume quantification of healthy paranasal cavity by three-dimensional CT imaging. Acta Otolaryngol. 1999; 119(540): 45-49, doi: 10.1080/00016489950181198.

18. Kim J, Song SW, Cho JH, et al. Comparative study of the pneumatization of the mastoid air cells and paranasal sinuses using three-dimensional reconstruction of computed tomography scans. Surg Radiol Anat. 2010; 32(6): 593-599, doi: 10.1007/s00276-009-0618-4, indexed in Pubmed: 20047049.

19. Lawson W, Patel ZM, Lin FY. The development and pathologic processes that influence maxillary sinus pneumatization. Anat Rec (Hoboken). 2008; 291(11): 1554-1563, doi: 10.1002/ar.20774, indexed in Pubmed: 18951496.
20. Lerno P. Identification par le sinus maxillaire. Odontol Leg. 1983; 216: 39-40.

21. Motro M. Hızlı üst çene genişletmesini takiben ve bir yıllık retansiyon dönemi sonrası maksiller sinüslerde meydana gelen değişikliklerin 3 boyutlu olarak incelenmesi. [Phd Thesis]. İstanbul: Marmara University. 2011.

22. Nuñez-Castruita A, López-Serna N, Guzmán-López S. Prenatal development of the maxillary sinus: a perspective for paranasal sinus surgery. Otolaryngol Head Neck Surg. 2012; 146(6): 997-1003, doi: 10.1177/0194599811435883, indexed in Pubmed: 22267494.

23. Orhan I, Ormeci T, Aydin S, et al. Morphometric analysis of the maxillary sinus in patients with nasal septum deviation. Eur Arch Otorhinolaryngol. 2014; 271(4): 727-732, doi: 10.1007/s00405-013-2617-7, indexed in Pubmed: 23832260.

24. Park IH, Song JS, Choi $\mathrm{H}$, et al. Volumetric study in the development of paranasal sinuses by CT imaging in Asian: a pilot study. Int J Pediatr Otorhinolaryngol. 2010; 74(12): 1347-1350, doi: 10.1016/j.ijporl.2010.08.018, indexed in Pubmed: 20863577.

25. Phothikhun S, Suphanantachat S, Chuenchompoonut V, et al. Cone-beam computed tomographic evidence of the association between periodontal bone loss and mucosal thickening of the maxillary sinus. J Periodontol. 2012; 83(5): 557-564, doi: 10.1902/jop.2011.110376, indexed in Pubmed: 21910593.

26. Saccucci M, Cipriani F, Carderi S, et al. Gender assessment through three-dimensional analysis of maxillary sinuses by means of cone beam computed tomography. Eur Rev Med Pharmacol Sci. 2015; 19(2): 185-193, indexed in Pubmed: 25683929.

27. Sahlstrand-Johnson $P$, Jannert $M$, Strömbeck $A$, et al. Computed tomography measurements of different dimensions of maxillary and frontal sinuses. BMC Med Imaging. 2011; 11: 8, doi: 10.1186/1471-2342-11-8, indexed in Pubmed: 21466703.

28. Thayyil S, Schievano S, Robertson NJ, et al. A semi-automated method for non-invasive internal organ weight estimation by post-mortem magnetic resonance imaging in fetuses, newborns and children. Eur J Radiol. 2009; 72(2): 321-326, doi: 10.1016/j.ejrad.2008.07.013, indexed in Pubmed: 18768277.

29. Uchida $Y$, Goto M, Katsuki T, et al. A cadaveric study of maxillary sinus size as an aid in bone grafting of the maxillary sinus floor. J Oral Maxillofac Surg. 1998; 56(10): 1158-1163, doi: 10.1016/s0278-2391(98)90761-3, indexed in Pubmed: 9766541.

30. Urooge A, Patil BA. Sexual dimorphism of maxillary sinus: a morphometric analysis using cone beam computed tomography. J Clin Diagn Res. 2017; 11(3): ZC67-ZC70, doi: 10.7860/ JCDR/2017/25159.9584, indexed in Pubmed: 28511513.

31. van den Bergh JP, ten Bruggenkate $C M$, Krekeler $G$, et al. Sinusfloor elevation and grafting with autogenous iliac crest bone. Clin Oral Implants Res. 1998; 9(6): 429-435, doi: 10.1034/j.1600-0501.1996.090608.x, indexed in Pubmed: 11429944. 